\title{
The qualitative-quantitative approach to microstructural characterization of nanostructured bainitic steels using electron microscopy methods
}

\author{
Aleksandra Królicka ${ }^{1, *}$, Aleksandra Janik ${ }^{2}$, Andrzej Żak ${ }^{1}$, Krzysztof Radwański $^{2}$ \\ ${ }^{1}$ Department of Metal Forming, Welding and Metrology, Wroclaw University of Science and Technology, Wybrzeże \\ Wyspiańskiego 27, 50-370 Wroclaw, Poland \\ ${ }^{2}$ Łukasiewicz Research Network-Institute for Ferrous Metallurgy, K. Miarki 12-14, 44-100 Gliwice, Poland
}

\begin{abstract}
Both qualitative and quantitative analyses play a key role in the microstructural characterization of nanobainitic steels focused on their mechanical properties. This research demonstrates various methods of microstructure analysis using transmission electron microscopy (TEM), scanning electron microscopy (SEM), and electron backscatter diffraction (EBSD) techniques, taking into account these two approaches. The structural constituents have been qualitatively characterized using TEM and selected area electron diffraction (SAED), together with quantitative analysis based on the misorientation angle (EBSD). Besides, quantitative measurement of austenite with both blocky and film-like morphologies has been carried out. Due to the scale of nanostructured bainite, it is also important to control the thickness of bainitic ferrite and film-like austenite; hence, a method for measuring their thickness is presented. Finally, the possibility of measuring the prior-austenite grain size by the EBSD method is also demonstrated and compared with the conventional grain boundary etching method. The presented methods of qualitative and quantitative analyses form a complementary procedure for the microstructural characterization of nanoscale bainitic steels.
\end{abstract}

Keywords: EBSD, TEM, SEM, bainite, grain size, retained austenite

\section{Highlights}

- Quantitative analysis of bainite is feasible using conventional electron microscopy methods

- Prior-austenite grain size determination requires the analysis of the misorientation angles

- Electron microscopy allows for distinguishing the retained austenite morphology quantitatively

- Evaluation of refinement level should be performed using TEM or high-resolution SEM methods

\footnotetext{
*E-mail: aleksandra.krolicka@pwr.edu.pl
}

\section{Introduction}

To this day, nanocrystalline bainitic steels - due to their well-known promising mechanical properties, especially tensile strength $>2,000 \mathrm{MPa}$ and elongation even to $14 \%[1-7,39,40]$ - are the subject of intensive research aimed at improving their microstructure. The structure of nanocrystalline bainitic steel consists of bainitic ferrite sheaves and retained austenite with blocky and film-like morphologies. The width of the austenite films and bainite laths is in the nanometric range - usually $<100$ $\mathrm{nm}$ [7]. The morphology of the retained austenite plays an important role in the context of mechanical behavior and properties [8]. Film-like austenite exhibits high carbon concentration, high dislocation density, and thus higher mechanical stability in comparison to blocky austenite [7, 8]. Moreover, the degree of refinement of the microstructural constituents is an important strengthening mechanism. Therefore, it is crucial to characterize bainitic microstructures using both qualitative and quantita- 
tive approaches. This research aims to present the possibilities of using electron microscopy methods for qualitative and quantitative analyses and to compare them.

This work also attempts to determine the prior austenite grain size (PAGS), which is crucial for achieving a high level of mechanical properties, especially toughness, in bainitic steels [9-12]. Moreover, in the context of bainitic transformation kinetics, the PAGS plays a crucial role regarding bainite nucleation rate [13], the bainitic transformation time [14-17], and bainitic transformation temperature [18]. Moreover, it has been stated that typical bainitic grade steels are prone to the growth of abnormal grains at high austenitization temperatures [11]. Furthermore, the well-known HallPetch effect directly associates the PAGS with dislocation movement, yield strength, and toughness [19]. Thus, determining both the distribution of grain size and its average value is an important material feature. In this investigation, the conventional process of revealing prior-austenite grains by etching with a picric acid solution was compared with the electron backscatter diffraction (EBSD) technique based on the analysis of misorientation angles.

Therefore, the aim of this work is to define a procedure enabling multifactorial assessment of the multiphase microstructure of refined bainitic steel. The investigations have been performed using conventional electron microscopy methods (scanning electron microscopy [SEM], transmission electron microscopy [TEM], and EBSD). An attempt is made to determine - both qualitatively and quantitatively - the fraction of retained austenite, taking into account its morphology (film-like or blocky). It should be emphasized that the majority of the methods used for quantifying the phases do not distinguish the morphology of retained austenite, which plays a key role in terms of its influence on the mechanical properties of bainitic steels. A method for assessing the refinement level of refinement of the microstructure (bainitic ferrite and film-like austenite) and the simple determination of prior-austenite grains size are also presented. Complementary application of the proposed procedures allows for a detailed and precise analysis of the structure without the use of highly specialized research equipment and software.

\section{Materials and methods}

\subsection{Research material}

The tested material was 9XC grade steel (GOST standard) after isothermal heat treatment, focused on obtaining low-temperature bainite with a high fraction of retained austenite. The high content of silicon $(\mathrm{Si})$ retards carbide precipitation from austenite [3, 4, 7, 20, 21]. In previous research [22], it was determined that 9XC grade steel is susceptible to formation of a nanobainitic structure. The steel in the as-received state is characterized by a microstructure consisting of spheroidal cementite and a ferrite matrix - typical for softening annealing. The chemical composition is presented in Table 1. The time-temperature-transformation (TTT) chart of the tested steel was obtained using phase transformation simulation (JMatPro software), presented in Figure 1. To obtain a refined bainitic structure with varied morphology of the retained austenite (both film-like and blocky), along with a reasonable period of heat treatment, austempering at $300{ }^{\circ} \mathrm{C}$ was applied. The simulated time of bainite transformation at this temperature was about $4.5 \mathrm{~h}$ (Figure 1). Based on the simulation of phase transformations, the martensite start $\left(\mathrm{M}_{\mathrm{s})}\right.$ temperature was about $132{ }^{\circ} \mathrm{C}$. This result is comparable to the analytical calculations presented in previous research [22], in which $\mathrm{M}_{\mathrm{s}}$ was in the range of $112-160{ }^{\circ} \mathrm{C}$. The heat treatment parameters are shown in Figure 2. To ensure a fully bainitic structure, the samples were isothermally treated for 5 h. The austenitization temperature was $1,000{ }^{\circ} \mathrm{C}$ to ensure homogeneous austenite. The hardness after the designed heat treatment was $525 \pm 5$ HV 30 .

Table 1. The chemical composition of 9XC steel.

Chemical composition, wt.\%

\begin{tabular}{llllllllll}
\hline \hline $\mathrm{C}$ & $\mathrm{Si}$ & $\mathrm{Mn}$ & $\mathrm{Cr}$ & $\mathrm{Mo}$ & $\mathrm{Al}$ & $\mathrm{Ni}$ & $\mathrm{P}$ & $\mathrm{S}$ & $\mathrm{V}$
\end{tabular}

$\begin{array}{lllllllllllllllllllllll}0.94 & 1.54 & 0.44 & 1.05 & 0.01 & 0.022 & 0.18 & 0.01 & 0.007 & 0.006\end{array}$ 


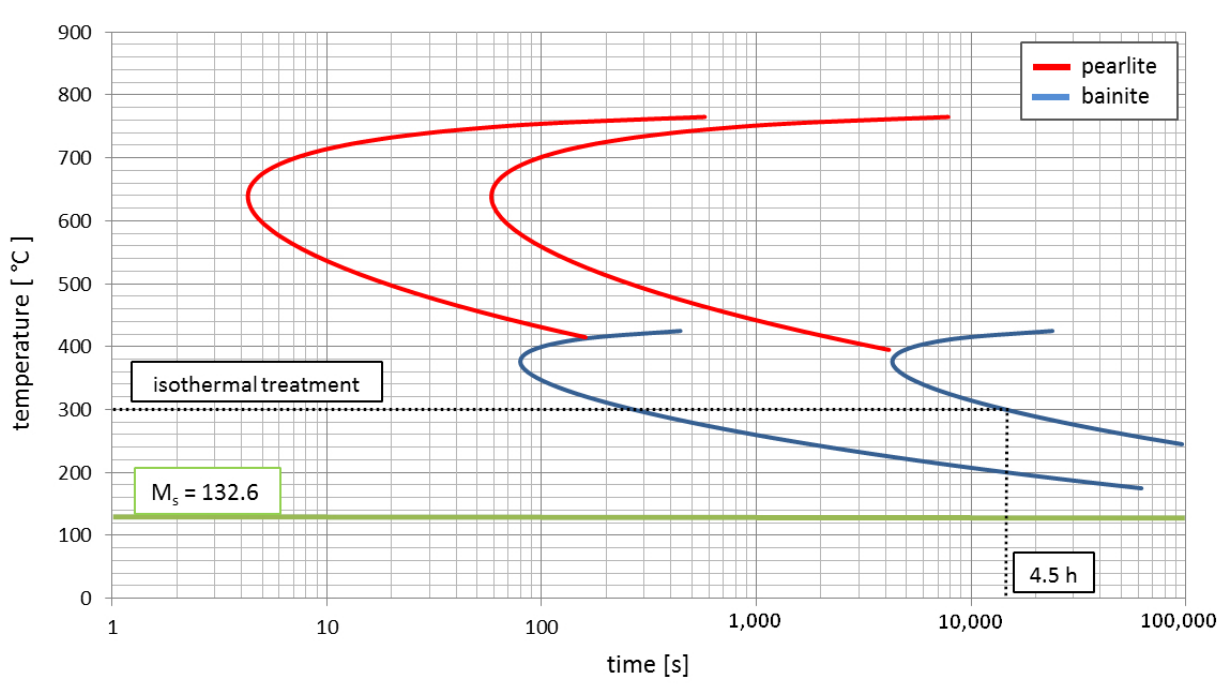

Fig. 1. TTT chart of 9XC steel, with indicated isotherm corresponding to the performed heat treatment. TTT, time-temperature-transformation.

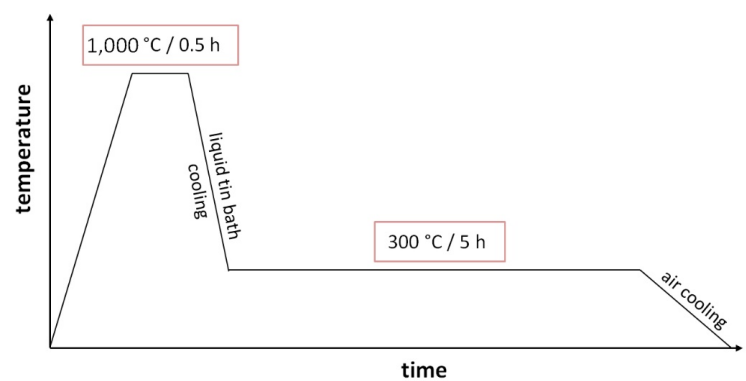

Fig. 2. Heat treatment diagram of the 9XC steel sample analyzed in this research.

\subsection{Methods}

Cuboidal samples of dimensions $(10 \mathrm{~mm} \times$ $10 \mathrm{~mm} \times 20 \mathrm{~mm}$ ) were used for PAGS and microstructural analysis. In the case of conventional picric acid solution etching, the samples were quenched (water cooled) and tempered. Due to the high Si content, which retards carbide precipitation [23, 24], the tempering process was necessary for an effective etching process. Similar to previously reported research [11], tempering was applied at $550{ }^{\circ} \mathrm{C}$ for $1 \mathrm{~h}$. The preparation of sample intended for PAGS analysis consisted of grinding using sandpapers (with number ranging from 120 to 1,200 ) and polishing using diamond medium (with diamond size ranging from $6 \mu \mathrm{m}$ to $1 \mu \mathrm{m}$ ). A saturated $5 \%$ picric acid solution in water at $60{ }^{\circ} \mathrm{C}$ was used for the etching process. PAGS was determined by measuring the diameters of the grains utilizing the ImageJ software. Grain diameters were defined as the arithmetic mean of the two diagonals of the grains.

The microstructural characterization included SEM, EBSD, and TEM analyses. The SEM observations were performed using a JEOL JSM7200F scanning electron microscope after etching with 3\% nital. The topographic contrast mode (secondary electron detector), an accelerating voltage of $15 \mathrm{kV}$, and a working distance of $10 \mathrm{~mm}$ were applied. The EBSD analysis was performed using the JEOL JSM-7200F scanning electron microscope equipped with EBSD and detector (Hikari Plus, EDAX). The data obtained during the investigations were processed utilizing the EDAX/TSL software. Investigations were performed on 25.3 $\mu \mathrm{m} \times 25.4 \mu \mathrm{m}$ areas with a step size of $60 \mathrm{~nm}$. Confidence index standardization and single-iteration grain dilation cleanup procedures were conducted. The grain size data were obtained considering a grain tolerance angle of $5^{\circ}$. The minimum grain size was determined at 2 pixels. The cleanup procedure did not exceed $>5 \%$ of the pixels.

Microstructure observations were also carried out using a HITACHI H-800 transmission elec- 
tron microscope. Preparation of samples intended for TEM investigations involved the mechanical prethinning of $0.5 \mathrm{~mm}$ plates to a thickness of 90-110 $\mu \mathrm{m}$. Then, the stamped disks with $\varnothing=3$ $\mathrm{mm}$ were electrochemically polished using the Struers TenuPol and ion polished using the GATAN DuoMill.

\section{Results}

\subsection{PAGS analysis}

Conventional etching with a solution of picric acid reveals the grain boundaries of the prior austenite from martensitic structures, described in the European Standards of the International Organization for Standardization (EN-ISO) 643:2019 standard. A solution of picric acid etches the primary carbides (probably epsilon carbide), which are released at the grain boundary of the prior austenite. The main problem with this method for bainitic steels is the presence of a high concentration of $\mathrm{Si}$, which effectively inhibits the precipitation of carbides, including epsilon carbide. Thus, often the grain boundary envelope is not visible without specific tempering processes directed toward precipitation processes. The results of conventional etching of 9XC grade steel are presented in Figure 3A. Moreover, to determine the PAGS by this method, a quenching process should be carried out for similar austenitization parameters; therefore, we should consider this measurement as indirect. On the other hand, EBSD analysis enables direct measurement because this analysis can be performed on samples after isothermal heat treatment aimed at obtaining a bainitic structure. Inside the grains of the prior austenite, the bainitic sheaves are characterized by various crystallographic orientations. It has been found that the angles, primarily in the range of $20^{\circ}-40^{\circ}$ in the case of martensitic structures, correspond to the boundaries of the prior-austenite grains [25]. This range of misorientation angles was also used for the bainitic structure (Figure 4). However, it should be highlighted that the misorientation angles in the mentioned range did not reveal a continuous envelope at the prioraustenite grain boundaries (Figure 4A,B, C). How- ever, the obtained results enable manual PAGS reconstruction based on both $20^{\circ}-40^{\circ}$ misorientation angles and bainitic sheaf orientation resulting from the inverse pole figure map (Figure 4D).

However, the obtained measurement results for the PAGSs (Table 2) and their distributions (Figures 3B and 5) indicate some discrepancies. Both the average diameter value and the median were significantly lower for the EBSD measurements (Table 2 ). The standard deviation (SD) was at a comparable level, while in the case of the semi-interquartile range $(1 / 2 \mathrm{IQR})$, these values were also significantly different $( \pm 8.0 \mu \mathrm{m}$ for the conventional method and $\pm 4.0 \mu \mathrm{m}$ for the EBSD technique). Due to the lower sensitivity to outliers, the median and IQR more accurately reflect the actual grain sizes. The distribution of grain diameters using the conventional method exhibits a slight right skewness (Figure 3B), while this cannot be found for the distribution obtained with the EBSD method, which is approximately normal (Figure 5).

\subsection{Microstructural characterization}

Due to the nanometric scale of the microstructural constituents of bainitic steel, the microstructural characterization should be performed using electron microscopy methods rather than with light microscopy. The first microstructure analysis includes SEM observations at relatively low magnifications to assess the homogeneity of the structure and the general morphology of bainite (Figure 6A). At higher magnifications, it is possible to identify film-like and blocky austenite morphologies and bainitic ferrite laths (Figure 6B). On the other hand, the unambiguous identification of bainitic sheaves should also include observations by TEM methods in the bright field (Figure 6C). Thus, it was found that after thermal heat treatment, the 9XC steel sample consists of bainitic sheaves, which consist of ferritic bainite and film-like austenite laths, as well as a significant blocky austenite fraction.

A clear distinction between the film-like austenite and the cementite plates occurring in the upper bainite was determined by selected area electron diffraction (SAED) from the bainitic sheaves area (Figure 7). The crystallographic orientation 

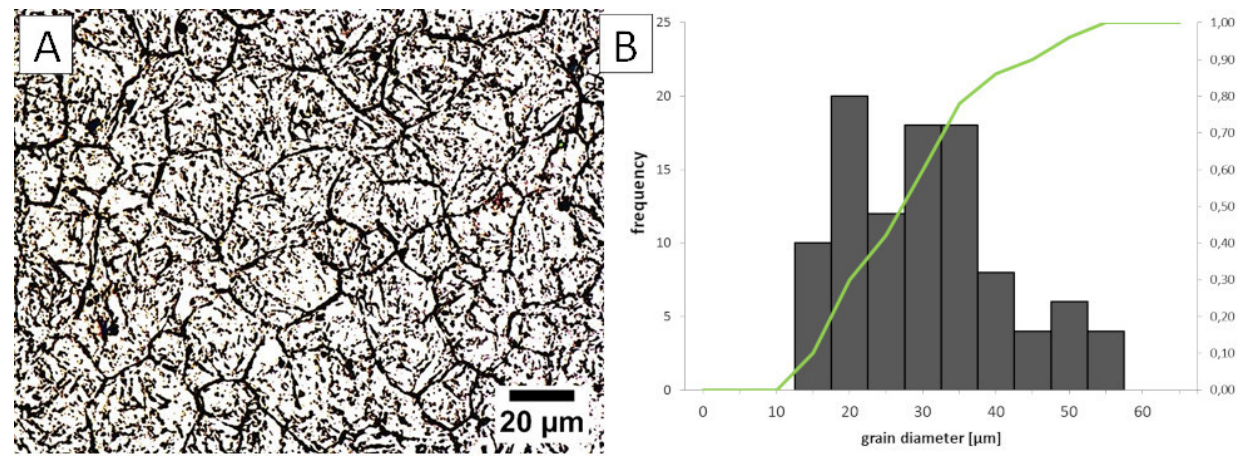

Fig. 3. PAGS analysis using a conventional picric acid solution. (A) Microphotography, light microscopy. (B) Grain diameter distribution. PAGS, prior-austenite grain size.

Table 2. Comparison of prior-austenite grain size measurements obtained by conventional etching by picric acid solution and by the EBSD technique.

\begin{tabular}{|c|c|c|c|c|c|c|}
\hline Measurement counts & $\bar{x}, \mathrm{~mm}$ & $\mathrm{SD}, \mathrm{mm}$ & Median, mm & $\mathrm{Q} 1, \mathrm{~mm}$ & $\mathrm{Q} 3, \mathrm{~mm}$ & $1 / 2 \mathrm{IQR}, \mathrm{mm}$ \\
\hline $\begin{array}{l}\text { Conventional etching by pi- } 100 \\
\text { cric acid solution }\end{array}$ & 27.8 & 10.9 & 26.4 & 18.9 & 34.9 & 8.0 \\
\hline $\begin{array}{l}\text { EBSD analysis using misori- } 100 \\
\text { entation angles }\left(20^{\circ}-40^{\circ}\right)\end{array}$ & 18.7 & 9.2 & 17.8 & 13.9 & 21.8 & 4.0 \\
\hline
\end{tabular}

EBSD, electron backscatter diffraction; 1/2IQR, semi-interquartile range; Q1, first quartile; Q3, third quartile; $\mathrm{SD}$, standard deviation; $\bar{x}$, average.

between bainitic ferrite and film-like austenite was consistent with the Kurdjumov-Sachs (K-S) orientation relationship (OR) (Figure 7C):

$$
[\overline{1} 01]_{\gamma}[\overline{11} 1]_{\alpha} ;(111)_{\gamma}(011)_{\alpha}
$$

The dark field image from the austenite reflex (111) also confirms the presence of retained austenite with a film-like morphology (Figure 7). After isothermal heat treatment, the tested steel - despite the high concentration of $\mathrm{Si}-$ also showed precipitation of cementite (Figure 8). The cementite precipitations are partially coherent with the ferritic and austenitic matrix (Figure 8A); however, they are not clearly visible in the bright field image (Figure 8B). Thus, the identification of the occurring phases was carried out using a qualitative approach. This approach is important in the context of the correct characterization of the microstructural constituents and is the basis for quantitative analysis.

To determine the morphology of the presented structural components, quantitative EBSD analysis was performed based on the misorientation angles. It was identified that bainitic sheaves were characterized by different crystallographic orientations (Figure 9A). Besides, the presence of both filmlike and blocky austenite was confirmed (Figure 9B). However, it should be emphasized that the EBSD technique does not detect the strongly refined austenite films that were identified by TEM. Quantitative analysis of the misorientation angles enables quantitative evaluation of both the crystallographic orientations and the related structural constituents. It can be noticed that in the tested area, the high-angle boundaries (HABs) in the range of $42^{\circ}-47^{\circ}$ were distinctly dominant (Figure 9D). In the case of nanobainitic steels, the misorientation angle of $46^{\circ}$ corresponds to the misorientation angle between bainitic ferrite and retained austenite, which is related to the ideal angle of the Nishiyama-Wassermann $(\mathrm{N}-\mathrm{W}) \mathrm{OR}-45.99^{\circ}$ [26]. However, the ideal angle of the K-S OR is $42.85^{\circ}$. The well-known $\mathrm{K}-\mathrm{S}$ and N-W ORs define the typical relations between ferrite and austenite; 


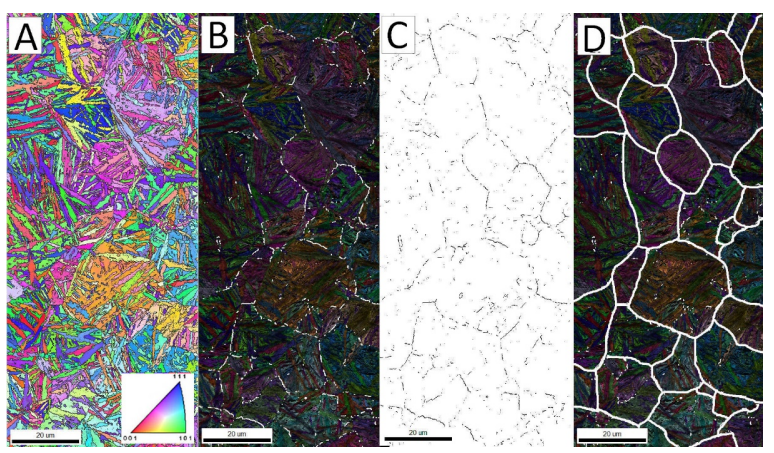

Fig. 4. PAGS analysis using the EBSD technique. (A) Inverse pole figure map. (B) Inverse pole figure and image quality map with the indicated misorientation angles in the range of $20^{\circ}-40^{\circ}$. (C) Misorientation angles in the range of $20^{\circ}-40^{\circ}$. (D) Inverse pole figure and image quality map with reconstructed prior-austenite grain boundaries based on misorientation angles and bainitic sheaves orientation. EBSD, electron backscatter diffraction; PAGS, prior austenite grain size.

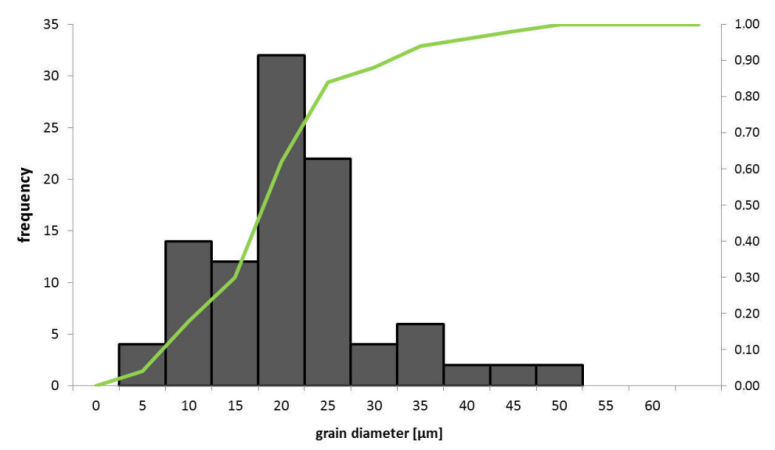

Fig. 5. Grain diameter distribution based on EBSD analysis of PAGS. EBSD, electron backscatter diffraction; PAGS, prior-austenite grain size, green line - cumulative histogram.

therefore, in the case of bainite steels, they indicate the presence of bainitic ferrite and retained austenite. This was also confirmed on the phase distribution maps with the $\mathrm{K}-\mathrm{S}$ and $\mathrm{N}-\mathrm{W}$ ideal angles (Figure 9C). It was also identified that the dominant orientation was the $\mathrm{N}-\mathrm{W}$ OR (approximately $25 \%$ ), rather than the K-S OR (approximately 16\%). Another peak of misorientation angle was found in the range of $55^{\circ}-60^{\circ}$. The misorientation angles between adjacent sheaves typically are $55^{\circ}$ and $60^{\circ}[25,27]$. It may also indicate the pres-

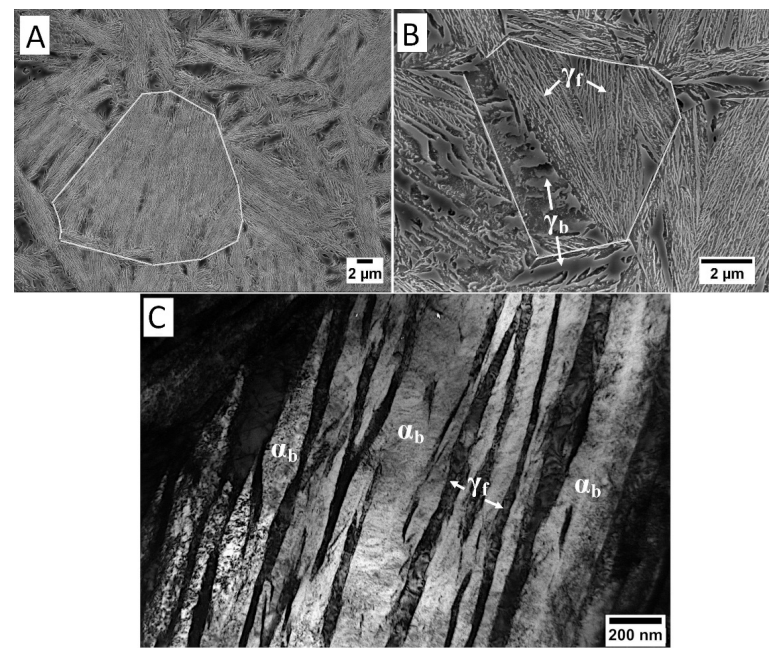

Fig. 6. The microstructure of 9XC steel after isothermal heat treatment. (A) Visible lath morphology of bainite sheaves inside the prior-austenite grain obtained by SEM. (B) Visible austenite with blocky $\left(\gamma_{\mathrm{b}}\right)$ and film-like $\left(\gamma_{\mathrm{f}}\right)$ morphologies inside the prior-austenite grain; image obtained by SEM. (C) Bainitic ferrite laths $\left(\alpha_{\mathrm{b}}\right)$ and filmlike austenite $\left(\gamma_{\mathrm{f}}\right)$ in the area of bainitic sheaves. Images were obtained by TEM (bright field image). SEM, scanning electron microscopy; TEM, transmission electron microscopy.

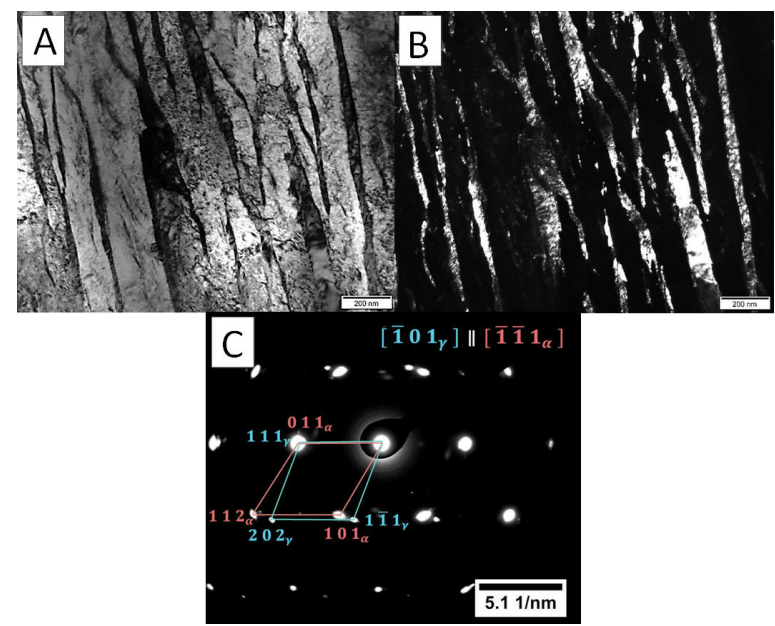

Fig. 7. (A) The bright field image of bainitic sheaves consisting of bainitic ferrite laths and film-like austenite. (B) The dark field image from the austenite reflex (111). (C) Selected area diffraction pattern with solution from the area presented in panel (A). TEM, $150 \mathrm{kV}$. TEM, transmission electron microscopy. 


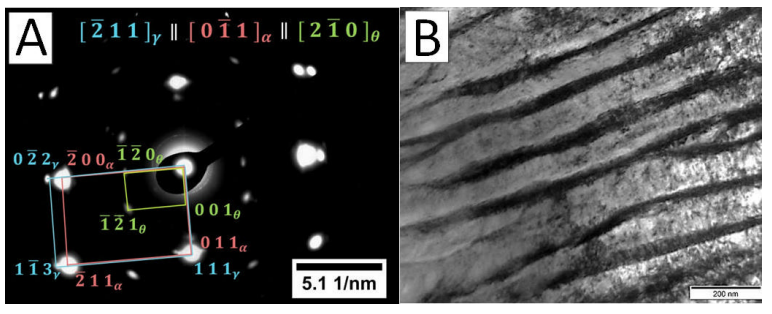

Fig. 8. (A) Selected area diffraction pattern with solution from area presented in panel (B) (B) The bright field image of bainitic sheaves consisting of bainitic ferrite laths, film-like austenite, and cementite precipitations. . TEM, $150 \mathrm{kV}$. TEM, transmission electron microscopy.

ence of martensite of lower bainite [27-29]; however, neither martensite nor lower bainite was confirmed in the TEM observations. Thus, these angles probably refer directly to the boundaries between the bainitic sheaves. A low fraction of low-angle boundaries (LABs) in the range of $2.5^{\circ}-8^{\circ}$ corresponds to lath-like subgrains inside bainitic ferrite laths [30].

\subsection{Microstructure refinement analysis}

To determine the degree of refinement of the microstructural constituents, the shortest distance perpendicular to the longitudinal dimension of the bainitic ferrite laths and film-like austenite was measured (Figure 10). Because the measurements were performed on random areas, stereological corrections were applied. The correction proposed in previous research [31, 32] was applied, based on which the obtained measurements were corrected by the factor of $\frac{\pi}{2}$. The measurement results are presented comparatively for both phases in Figures 11 and 12 and Table 3. The width distribution of the bainitic ferrite laths and the austenite films exhibits a slight right skewness. It can also be seen that the overall thickness of the bainitic ferrite was more than that of the film-like austenite (Figure 11). The width of the film-like austenite was in the nanometric range ( $\bar{x}: 44.6 \mathrm{~nm} \pm 20.3 \mathrm{~nm}$ and median: 40.0 $\mathrm{nm} \pm 10.4 \mathrm{~nm}$; Table 3 ), while the width of bainitic ferrite laths slightly exceeds $100 \mathrm{~nm}(\bar{x}: 106.8 \mathrm{~nm}$ $\pm 40.7 \mathrm{~nm}$ and median: $102.0 \mathrm{~nm} \pm 27.7 \mathrm{~nm}$; Table 3$)$. The scatter resulting from the measurements

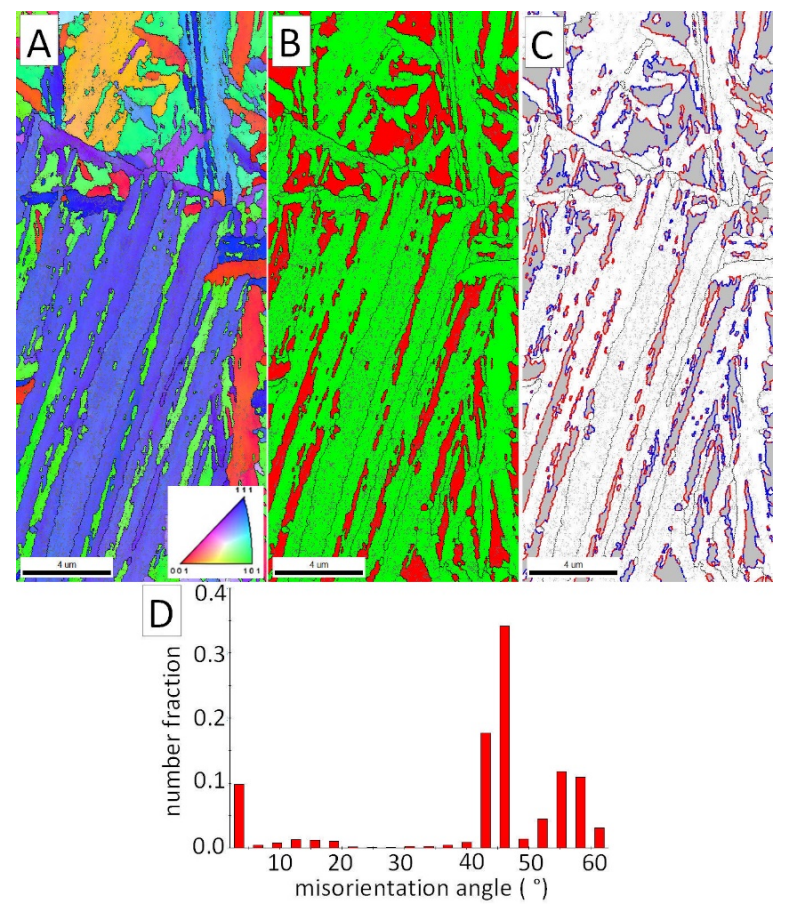

Fig. 9. (A) Inverse pole figure map of 9XC grade steel after isothermal heat treatment. (B) Phase distribution map. Ferrite is marked in green, austenite is marked in red. (C) Phase distribution map (ferrite - white, austenite - gray), with the indicated $\mathrm{K}-\mathrm{S}$ misorientation angles $\left(43^{\circ} \pm 1\right)$ in red and $\mathrm{N}-\mathrm{W}$ misorientation angles $\left(46^{\circ} \pm 1\right)$ in blue. (D) Distribution of the misorientation angles. $\mathrm{K}-\mathrm{S}$, Kurdjumov-Sachs; $\mathrm{N}-\mathrm{W}$, Nishiyama-Wassermann.

is clearly visible on the boxplots, which indicates that many more outliers occur for film-like austenite (Figure 12). In summary, the tested 9XC steel after isothermal heat treatment can be classified at the limit of the nanometric scale.

\subsection{Quantitative analysis of retained austenite}

Due to the significant role of the retained austenite morphology on the mechanical properties of nanobainitic steels, the quantification of both film-like and blocky morphologies is particularly important. Only based on microscopic observations is it possible to estimate their ratio. Two methods of quantifying both morphologies are proposed. One of them is based on the graphi- 
Table 3. Results of measurement of the thicknesses of film-like austenite and bainitic ferrite.

\begin{tabular}{llllllll}
\hline Phase & \multicolumn{1}{c}{ Count number } & $\bar{x}, \mathrm{~nm}$ & $\mathrm{SD}, \mathrm{nm}$ & Median, $\mathrm{nm}$ & $\mathrm{Q} 1, \mathrm{~nm}$ & $\mathrm{Q} 3, \mathrm{~nm}$ & 1/2IQR, nm \\
\hline \hline Filmy austenite & 131 & 44.6 & 20.3 & 40.0 & 32.5 & 53.4 & 10.4 \\
Bainitic ferrite & 131 & 106.8 & 40.7 & 102.0 & 76.3 & 131.8 & 27.7
\end{tabular}

1/2IQR, semi-interquartile range; Q1, first quartile; Q3, third quartile; SD, standard deviation; $\bar{x}$, xxx.

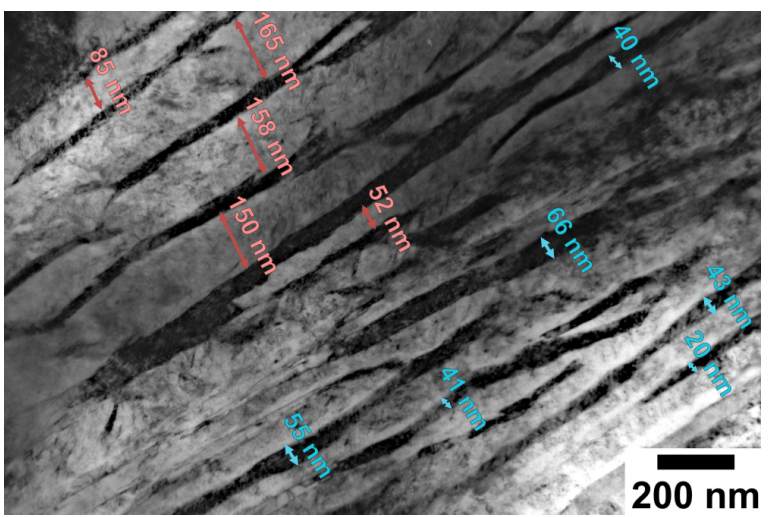

Fig. 10. Example of an image used for phase refinement analysis. TEM, bright field image. TEM, transmission electron microscopy.

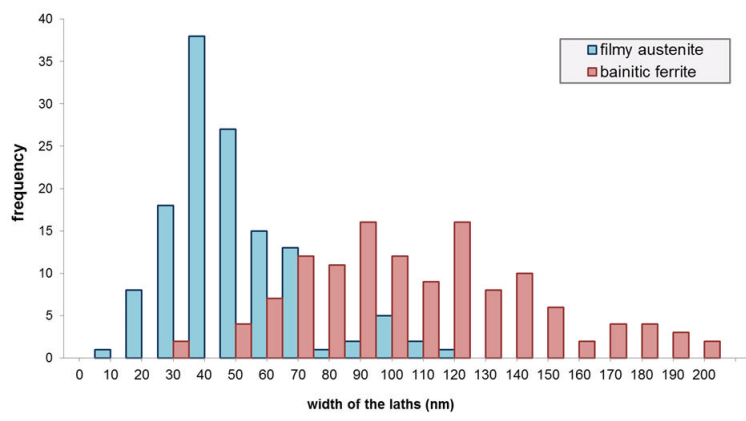

Fig. 11. The widthdistribution of film-like austenite and bainitic ferrite.

cal analysis of SEM images in a topographic contrast (secondary electron mode), presented in Figure 13. The amount of film-like austenite was determined using threshold and area fraction measurements (Figure 13C). Due to the similar contrast of blocky austenite and bainitic ferrite, the blocky austenite regions were defined manually (Figure 13D). The second method was to consider separately the blocky austenite, determined based on the EBSD technique (phase distribution map), and the austenite with film-like morphology, calcu-

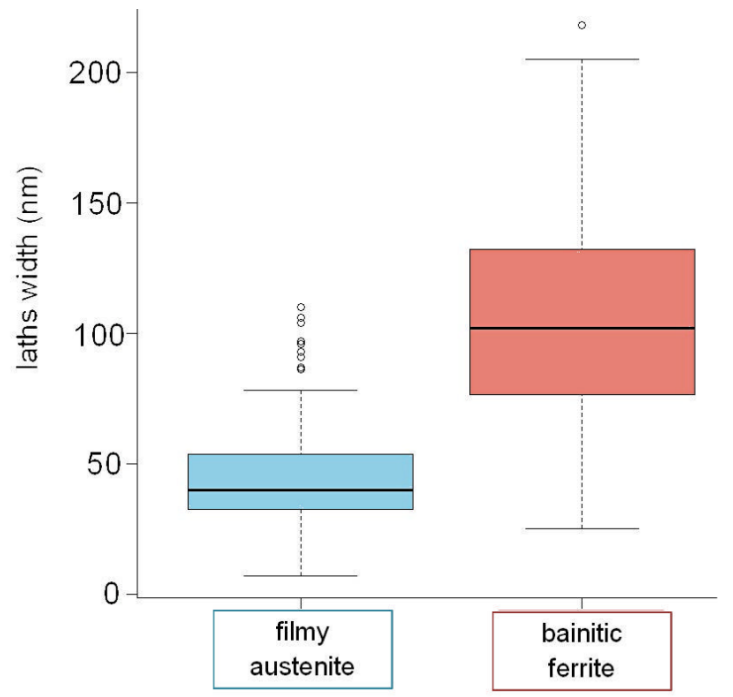

Fig. 12. Box plot of the thicknesses of film-like austenite and bainitic ferrite.

lated from the bright field images (TEM method). It should be emphasized that to correctly determine the blocky austenite in the EBSD technique, appropriate magnification should be used. Thus, the measurement result depends on the selected research areas, which should be representative and comparable. Graphical analysis of images in the bright field (TEM) was performed using the threshold and manual tracing of austenite with film-like morphology (Figure 14). Because very small areas are analyzed in this method and since the measurement may also be affected by the different orientations of the bainitic sheaves, this method requires a series of measurements. Table 4 compares the results obtained with the two described methods. The results are generally comparable between the methods but should be regarded as an estimate. In both methods, the fraction of film-like austenite was slightly higher than that of blocky austenite. 
Table 4. Measurement results of retained austenite content considering its morphology.

\begin{tabular}{llllll}
\hline Method & $\begin{array}{l}\text { Measurement } \\
\text { areas }\end{array}$ & \multicolumn{3}{l}{ Blocky austen- Film-like austen- Total austenite Ratio, $\gamma_{f} / \gamma_{b}$} \\
& ite $\left(\gamma_{b}\right), \%$ & ite $\left(\gamma_{f}\right), \%$ & $\left(\gamma_{b}+\gamma_{f}\right), \%$ & \\
\hline \hline SEM - graphical analysis & 3 & $20.5 \pm 3.2$ & $23.7 \pm 4.1$ & 44.2 & 1.16 \\
EBSD - phase distribution map & 3 & $22.3 \pm 5.8$ & - & - & - \\
TEM - graphical analysis & 5 & - & $24.8 \pm 9.1$ & - & - \\
TEM + EBSD & - & $22.3 \pm 5.8$ & $24.8 \pm 9.1$ & 47.1 & 1.11 \\
\hline
\end{tabular}

$\gamma_{\mathrm{b}}$, blocky austenite; $\gamma_{\mathrm{f}}$, film-like austenite; EBSD, electron backscatter diffraction; SEM, scanning electron microscopy; TEM, transmission electron microscopy.

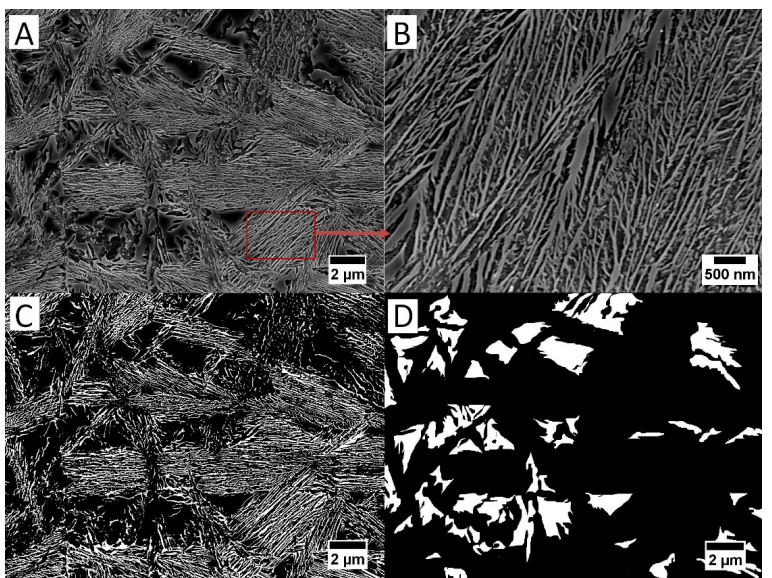

Fig. 13. (A) Example of area intended for qualitative analysis. (B) Magnification of bainitic sheaf. Visible film-like austenite and bainitic ferrite. (C) Graphic image editing intended for filmlike austenite measurements. (D) Prepared image for blocky austenite measurements.

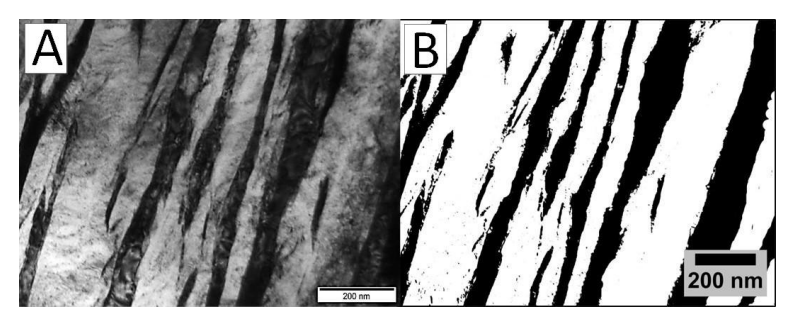

Fig. 14. (A) Bright field image of bainitic sheaf (TEM). (B) Prepared image for area fraction measurement of film-like austenite. TEM, transmission electron microscopy.

\section{Discussion}

Quantitative analysis is important in the design of new grades of bainitic steel; however, this approach should always be supported by qualitative analysis. The identification of the bainite morphology should be based on both SEM and TEM/SAED methods to determine all the structural constituents present. Although carbide precipitation was not visible in the SEM images, its presence was confirmed by TEM/SAED, which enabled the conclusion that the structure is not completely carbide free. Despite the high concentration of $\mathrm{Si}$, the precipitation of cementite in bainite ferrite was also found in previous research [33]. Moreover, no presence of martensite and lower bainite was found after isothermal heat treatment of 9XC grade steel. Moreover, the analysis of the misorientation angle distribution made it possible to quantify the microstructure. A large proportion of HABs in the range of $42^{\circ}-47^{\circ}$ corresponded to the typical crystallographic orientations between ferrite and austenite, i.e., $\mathrm{K}-\mathrm{S}$ and $\mathrm{N}-\mathrm{W}$ ORs, which has also been confirmed for another high-Si hypereutectoid steel [34]. On this basis, the dominant orientation was also determined. In the case of the tested steel, the N-W OR was dominant, which is consistent with previous research, where the $\mathrm{N}-\mathrm{W}$ ORs dominated at higher isothermal annealing temperatures [35]. A significant proportion of HABs in the range of $55^{\circ}-60^{\circ}$ was also found, which corresponded to the boundaries between bainitic sheaves with different orientations. Finally, a small fraction of LABs in the range of $2.5^{\circ}-8^{\circ}$ corresponded to lath-like subgrains inside bainitic ferrite laths [30]. Together with the qualitative analysis, this distribution confirmed the presence of low-temperature bainite consisting of bainitic ferrite and retained austenite. However, it should be mentioned that 
without previously performing identification of the structural constituents, the misorientation angles may be incorrectly interpreted. The morphology of retained austenite is of particular importance in the context of mechanical properties and behavior $[3,4,7,8,36]$. The distinction between blocky and film-like austenite can be performed using SEM and TEM methods. For this reason, the ratio of film-like-to-blocky austenite plays a crucial role. In another investigation [37], a method to determine the ratio of both retained austenite morphologies, based on graphical analysis of TEM images to determine film-like austenite content and X-ray diffraction to determine the total content of retained austenite, was proposed. In this study, two methods were presented based on the graphical analysis of SEM and TEM images and quantitative phase analysis using the EBSD technique. Both methods exhibited comparable content and proportions of blocky and film-like austenite. However, due to a large possible error in determining the threshold level, these results should be treated as an estimation. Improving the accuracy of the measurements will also depend on the number of repetitions of this procedure. In the quantitative analysis using EBSD, the optimal magnification should also be determined, which will allow for the analysis of blocky austenite without any film-like austenite. The degree of refinement of the microstructure is determined from the bright field images (TEM method) with the application of stereographic correction [31, 32]. The reliability of the results for the thicknesses of the film-like austenite and bainitic ferrite lath depends on the number of measurements made and their randomness, which can be determined by histograms and boxplot plots based on medians and quartiles. The distribution of the thicknesses showed a slight right skewness, with more outliers in the case of film-like austenite. For this reason, the median and $1 / 2 \mathrm{IQR}$ describe the thickness dimensions of these phases better than the mean and SD. In general, austenite with filmlike morphology was characterized by a higher degree of refinement $(40.0 \mathrm{~nm} \pm 10.4 \mathrm{~nm})$ than bainitic ferrite laths $(102.0 \mathrm{~nm} \pm 27.7 \mathrm{~nm})$.

Revealing the prior-austenite grains in steels with a high concentration of $\mathrm{Si}$ may be diffi- cult due to the retaining effect of carbide precipitation [23, 24], which is necessary for etching with conventional picric acid solution. In previous research [11], it was determined that tempering at temperatures $>500{ }^{\circ} \mathrm{C}$ enables the formation of an envelope at the boundary of the prioraustenite grains after etching with picric acid. In contrast, in the current investigation, PAGS measurements using the EBSD technique and misorientation angles in the range of $20^{\circ}-40^{\circ}$ are proposed, which - in martensitic steels - correspond to the prior-austenite grain boundaries [25]. On this basis, a discontinuous envelope was formed at the prior-austenite grain boundaries, which required reconstruction also based on the orientation of the bainitic sheaves (inverse pole figure map). In the case of high heterogeneity of distribution, the median and $1 / 2 \mathrm{IQR}$ more precisely describe the PAGS [11]. The comparison of the two methods showed that the PAGS determined by the EBSD technique is generally smaller $(17.8 \mu \mathrm{m} \pm 4.0 \mu \mathrm{m})$ than that obtained using the conventional picric acid etching technique $(26.4 \mu \mathrm{m} \pm 8.0 \mu \mathrm{m})$. This may be caused by errors during the grain reconstruction process. It should also be noted that the $20^{\circ}-40^{\circ}$ angles not only correspond to the boundaries of the prior austenite but also can belong to the other $\mathrm{K}-\mathrm{S}$ or $\mathrm{N}-\mathrm{W}$ OR variants (24 and 12 variants, respectively $[35,38])$. However, the advantage of the EBSD technique is the possibility of observing the grain boundaries after isothermal heat treatment (bainitic structure), and in the case of conventional etching, after the quenching and tempering processes (martensite structure).

Thus, the presented methods of quantitative and qualitative analyses using electron microscopy methods allow for a complete assessment of the microstructure of the nanobainitic steel. However, due to the small measurement area, an appropriate number of repetitions should be used to ensure greater accuracy of the results. Moreover, the quantitative approach can also be misinterpreted without the qualitative analysis. Therefore, these studies should be conducted in parallel. 


\section{Conclusions}

Microstructural characterization using both qualitative and quantitative approaches is described in this work. The complementary use of both approaches enables the complete characterization of nanobainitic steels. Based on the analysis of the obtained results, the following conclusions are formulated:

The PAGS analysis can be performed by EBSD by analyzing the misorientation angles in the range of $20^{\circ}-40^{\circ}$. However, it should be noted that continuous envelopes may not form at the grain boundaries, which requires reconstruction of the grains based on the orientation of the bainitic sheaves. The PAGS determined by the EBSD method was smaller than that obtained by conventional picric acid etching, which may have been influenced by the grain reconstruction procedure.

Despite the high concentration of $\mathrm{Si}$, the obtained structure was not carbide free. The presence of partially coherent cementite precipitation was determined based on TEM/SAED, but they were not visible in bright field images.

Based on the distribution of the misorientation angles, together with qualitative analysis, other microstructural constituents such as martensite or lower bainite can be excluded or confirmed.

Thickness measurements of bainitic ferrite and film-like austenite based on bright field images (TEM) enabled the classification of 9XC steel after isothermal heat treatment as nanostructured steel. The median and IQR more precisely describe the degree of refinement than the average and SD due to lower susceptibility to outliers. The ratio of filmlike austenite to blocky austenite can be determined by SEM and TEM image graphical analysis, as well as with phase distribution maps (EBSD). Based on the comparison of the proposed measurement methods, it was found that their results are generally similar. The results of these measurements should be treated as estimates because they strongly depend on the applied threshold level, magnification, and microstructural homogeneity.

Strongly refined film-like austenite is not detected by the conventional EBSD technique; therefore, its presence should be confirmed by TEM or high-resolution SEM methods for proper quantification.

The raw/processed data required to reproduce these findings cannot be shared at this time as the data also form part of an ongoing study.

\section{Acknowledgements}

This work was performed as part of the research project number 2020/37/N/ST8/03324, financed by the National Science Centre (Kraków, Poland).

\section{References}

[1] Caballero FG, Bhadeshia HKDH, Mawella KJA, Jones DG, Brown P. Design of novel high strength bainitic steels: part 1. Mater Sci Technol. 2001;17:512-6. https://doi.org/10.1179/026708301101510348.

[2] Caballero FG, Bhadeshia HKDH, Mawella KJA, Jones DG, Brown P. Design of novel high strength bainitic steels: part 2. Mater Sci Technol. 2001;17:517-22. https://doi.org/10.1179/026708301101510357.

[3] Caballero FG, Bhadeshia HKDH, Mawella KJA, Jones DG, Brown P. Very strong low temperature bainite. Mater Sci Technol. 2002;18:279-84.

[4] Caballero FG, Bhadeshia HKDH. Very strong bainite. Curr Opin Solid State Mater Sci. 2004;8:251-7.

[5] Garcia-Mateo C, Caballero FG. Ultra-high-strength Bainitic Steels. ISIJ Int. 2005;45:1736-40.

[6] Garcia-Mateo C, Caballero FG. Design of carbide-free low-temperature ultra high strength bainitic steels. Int J Mater Res. 2007;98:137-43.

[7] Bhadeshia HKDH. Nanostructured bainite. Proc R Soc A Math Phys Eng Sci. 2010;466:3-18.

[8] Dong B, Hou T, Zhou W, Zhang G, Wu K. The role of retained austenite and its carbon concentration on elongation of low temperature bainitic steels at different austenitising temperature. Metals (Basel). 2018;8:931.

[9] Li X, Ma X, Subramanian SV, Shang C, Misra RDK. Influence of prior austenite grain size on martensiteaustenite constituent and toughness in the heat affected zone of 700MPa high strength linepipe steel. Mater Sci Eng A. 2014;616:141-7.

[10] Jiang T, Liu H, Sun J, Guo S, Liu Y. Effect of austenite grain size on transformation of nanobainite and its mechanical properties. Mater Sci Eng A. 2016;666:207-13.

[11] Królicka A, Radwański K, Ambroziak A, Żak A. Analysis of grain growth and morphology of bainite in medium-carbon spring steel. Mater Sci Eng A. 2019;768:138446.

[12] Lan HF, Du LX, Li Q, Qiu CL, Li JP, Misra RDK. Improvement of strength-toughness combination in austempered low carbon bainitic steel: the key role of refining prior austenite grain size. J Alloys Compd. 2017;710:702-10.

[13] Yamamoto S, Yokoyama H, Yamada K, Niikura M. Effects of the austenite grain size and deformation in the unrecrystallized austenite region on bainite 
transformation behavior and microstructure. ISIJ Int. 1995;35:1020-6.

[14] Lee S-J, Park J-S, Lee Y-K. Effect of austenite grain size on the transformation kinetics of upper and lower bainite in a low-alloy steel. Scr Mater. 2008;59:87-90.

[15] Rees GI, Bhadeshia HKDH. Bainite transformation kinetics Part 1 modified model. Mater Sci Technol. 1992;8:985-93.

[16] Xu G, Liu F, Wang L, Hu H. A new approach to quantitative analysis of bainitic transformation in a superbainite steel. Scr Mater. 2013;68:833-6.

[17] Matsuzaki A, Bhadeshia HKDH. Effect of austenite grain size and bainite morphology on overall kinetics of bainite transformation in steels. Mater Sci Technol. 1999;15:518-22.

[18] Kang S, Yoon S, Lee S-J. Prediction of bainite start temperature in alloy steels with different grain sizes. ISIJ Int. 2014;54:997-9.

[19] Whang SH. Nanostructured metals and alloys Processing, Microstructure, Mechanical Properties and Applications, Woodhead Publishing Series in Metals and Surface Engineering. Elsevier; 2011, Cambridge.

[20] Chen Z, Gu J, Han L. Decomposition characteristic of austenite retained in $\mathrm{GCr} 15$ bearing steel modified by addition of $1.3 \mathrm{wt} . \%$ silicon during tempering. J Mater Res Technol. 2019;8:157-66.

[21] Kozeschnik E, Bhadeshia HKDH. Influence of silicon on cementite precipitation in steels. Mater Sci Technol. 2008;24:343-7.

[22] Baran D, Królicka A. Evaluation of the possibility to obtain nanostructured bainite in high-carbon and high-silicon 9XC bearing steel. J Mater Eng Perform. 2020;29:5329-36.

[23] Zhu K, Shi H, Chen H, Jung C. Effect of Al on martensite tempering: comparison with Si. J Mater Sci. 2018;53:6951-67.

[24] Miyamoto G, Oh J, Hono K, Furuhara T, Maki T. Effect of partitioning of $\mathrm{Mn}$ and $\mathrm{Si}$ on the growth kinetics of cementite in tempered $\mathrm{Fe}-0.6$ mass \% C martensite. Acta Mater. 2007;55:5027-38.

[25] Beladi H, Rohrer GS, Rollett AD, Tari V, Hodgson PD. The distribution of intervariant crystallographic planes in a lath martensite using five macroscopic parameters. Acta Mater. 2014;63:86-98.

[26] Beladi H, Adachi Y, Timokhina I, Hodgson PD. Crystallographic analysis of nanobainitic steels. Scr Mater. 2009;60:455-8.

[27] Gourgues AF, Flower HM, Lindley TC. Electron backscattering diffraction study of acicular ferrite, bainite, and martensite steel microstructures. Mater Sci Technol. 2000;16:26-40.
[28] Królicka A, Radwański K, Janik A, Kustroń P, Ambroziak A. Metallurgical characterization of welded joint of nanostructured bainite: regeneration technique versus post welding heat treatment. Materials (Basel). 2020;13. https://doi.org/10.3390/ma13214841.

[29] Radwański K. Structural characterization of low-carbon multiphase steels merging advanced research methods with light optical microscopy. Arch Civ Mech Eng. 2016;16:282-93.

[30] Suikkanen PP, Cayron C, DeArdo AJ, Karjalainen LP. Crystallographic analysis of isothermally transformed bainite in $0.2 \mathrm{C}-2.0 \mathrm{Mn}-1.5 \mathrm{Si}-0.6 \mathrm{Cr}$ steel using EBSD. J Mater Sci Technol. 2013;29:359-66.

[31] Chang LC, Bhadeshia HKDH. Austenite films in bainitic microstructures. Mater Sci Technol. 1995;11:874-82.

[32] Garcia-Mateo C, Jimenez JA, Lopez-Ezquerra B, Rementeria R, Morales-Rivas L, Kuntz M, et al. Analyzing the scale of the bainitic ferrite plates by XRD, SEM and TEM. Mater Charact. 2016;122:83-9.

[33] Timokhina IB, Beladi H, Xiong XY, Adachi Y, Hodgson PD. Nanoscale microstructural characterization of a nanobainitic steel. Acta Mater. 2011;59:5511-22.

[34] Chen Z, Gu J, Han L. Bainite transformation characteristics of high-si hypereutectoid bearing steel. Metallogr Microstruct Anal. 2018;7:3-10.

[35] Beladi H, Tari V, Timokhina IB, Cizek P, Rohrer GS, Rollett $\mathrm{AD}$, et al. On the crystallographic characteristics of nanobainitic steel. Acta Mater. 2017;127:426-37.

[36] Kumar A, Makineni SK, Dutta A, Goulas C, Steenbergen M, Petrov RH, et al. A design of high-strength and damage-resistant carbide-free fi ne bainitic steels for railway crossing applications. Mater Sci Eng A. 2019;759:210-23

[37] Bhadeshia HKDH, Edmonds DV. Bainite in silicon steels: new composition-property approach Part 1 . Met Sci. 1983;17:411-9.

[38] Kitahara H, Ueji R, Ueda M, Tsuji N, Minamino Y. Crystallographic analysis of plate martensite in Fe-28.5 at.\% Ni by FE-SEM/EBSD. Mater Charact. 2005;54:378-86.

[39] Garcia-Mateo C, Caballero FG, Bhadeshia HKDH. Superbainite. A novel very strong bainitic microstructure. Rev Metal. 2005;41:186-93.

[40] Bhadeshia HKDH. Case study: design of bainitic steels. Mater Sci. n.d.;1-6. https://www.phasetrans.msm.cam.ac.uk/2000/C9/C9-8.pdf.

Received 23-07-2021

Accepted 16-08-2021 